\title{
MALVINAS (FALKLAND) PLATEAU STRUCTURE VERSUS MJØLNIR CRATER: GEOPHYSICAL WORKFLOW TEMPLATE FOR PROPOSED MARINE IMPACT CRATERS
}

\begin{tabular}{|r|l|}
\hline Journal: & Meteoritics \& Planetary Science \\
\hline Manuscript ID & MAPS-3041.R1 \\
\hline Manuscript Type: & Article \\
\hline Date Submitted by the Author: & n/a \\
\hline Complete List of Authors: & $\begin{array}{l}\text { Tsikalas, Filippos; University of Oslo, Department of Geosciences } \\
\text { Eldholm, Olav; University of Bergen, Department of Earth Science }\end{array}$ \\
\hline Keywords: & $\begin{array}{l}\text { Mjølnir Crater, Malvinas Plateau Structure, marine impact craters, } \\
\text { geophysical template }\end{array}$ \\
\hline & \\
\hline
\end{tabular}

\section{SCHOLARONE ${ }^{\text {m }}$}

Manuscripts 


\section{MALVINAS (FALKLAND) PLATEAU STRUCTURE VERSUS MJØLNIR CRATER: \\ GEOPHYSICAL WORKFLOW TEMPLATE FOR PROPOSED MARINE IMPACT CRATERS}

Tsikalas, F. $^{1,2^{*}}$ and Eldholm, $\mathrm{O}^{3}$

${ }^{1}$ Eni Norge AS, P.O. Box 101 Forus, NO-4064 Stavanger, Norway;

${ }^{2}$ Department of Geosciences, University of Oslo, P.O. Box 1047 Blindern, NO-0316 Oslo, Norway;

${ }^{3}$ Department of Earth Science, University of Bergen, P.O. Box 7803, NO-5020 Bergen, Norway;

(filippos.tsikalas@geo.uio.no; olav.eldholm@uib.no)

*corresponding author (filippos.tsikalas@geo.uio.no) 


\section{ABSTRACT}

A diagnostic geophysical-based template, supported by modelling, is suggested to be used prior to, or in combination with geological/drilling data, when proposing a marine impact crater. The latter refers to impacts occurring in a marine setting and resulting in structures that are currently partially or totally underwater. The methodology is based on the welldocumented Mjølnir Crater in the Barents Sea. The template has been developed in conjunction with the recently proposed and debated impact crater on the Malvinas (Falkland) Plateau in the South Atlantic. Despite their different sizes, their comparison adds to the ambiguous nature of the Malvinas structure and shows that the integrated analysis of seismic and potential field data and modelling is crucial for any interpretation of a marine impact crater without relevant geological information. The proposed workflow template utilises all available geophysical data and is composed of a series of iterative steps, including a range of alternative non-impact interpretations that must be discussed and accounted for. Subsequently, further iterative geophysical modelling is required to support and decipher the impact related processes. A more complex impact crater model and additional impact crater features can be resolved by physical property modelling. In all cases, a close spatial correspondence of the defined impact structure with potential field anomalies is a necessity to establish a causal relationship. We suggest that the diagnostic workflow template provides a methodology to be applied to future studies of the Malvinas structure, as well as to proposed marine (and, with minor adaptions, to non-marine) impact craters in general. 


\section{INTRODUCTION}

Recently, Rocca et al. (2017) proposed a buried Late Paleozoic impact crater on the Malvinas (Falkland) Plateau in the South Atlantic Ocean; at a location where Rampino (1992) had previously suggested an impact structure (Fig. 1a). For brevity, we denote the feature the Malvinas structure. The main evidence derives from a seismic profile, as well as gravity and magnetic anomalies. However, their 'contentious' inference has caused some disquiet (McCarthy et al. 2017; Reimold et al. 2017) to which the authors have rebutted (Rampino et al. 2017).

During the past decades, we and our colleagues have explored the earliest Berriasian Mjølnir impact crater in the epicontinental Barents Sea, adjacent to the North Atlantic Ocean (Fig. 1b) (e.g., Tsikalas et al. 2002a-b, 2010a-b; Dypvik et al. 2010). In fact, its character and geological and geophysical signatures, together with extensive modelling substantiate that Mjølnir is a well-documented, and recognized (Earth Impact Database 2018) marine impact crater that can be related to the Malvinas structure debate. Except for cursory remarks by Rampino et al. (2017), the recent Malvinas papers do not consider the numerous studies of the well-preserved Mjølnir Crater. Keeping in mind the smaller size of Mjølnir, we discuss the two structures in order to contribute towards the ambiguous nature of the Malvinas structure. Our main, and more substantial, objective is that we recognize the need to establish a diagnostic geophysical-based template, supported by modelling, to be used prior to or in combination with geological/drilling data when proposing a marine impact structure in sedimentary targets.

\section{MARINE IMPACT CRATERS: LIMITED DATA LEAD TO CONTROVERSIES}

Despite the fact that marine impact craters have greater preservation potential than subaerial ones because water and post-impact sediments shield the primary impact features from erosion (e.g., Tsikalas et al. 2002a) only a limited number have been proposed globally; most of which are located in shallow waters, i.e., on continental shelves and in epicontinental seas. However, even including unconfirmed impact structures, the total number is still far lower than that in continents (Earth Impact Database 2018). The limited number of marine impact 
structures still remains despite the fact that oceanic crust may have been subducted and that small marine impacts may not leave an unambiguous record. In the paper, we use the term marine impact structures for impacts that occurred in a marine setting and resulted in structures that are currently partially or totally underwater. Of these, the Chicxulub (Gulick et al. 2013; Kring et al. 2016; Christeson et al. 2018), Mjølnir (Gudlaugsson et al. 1993; Dypvik et al. 1996, 2010), Chesapeake Bay (Koeberl et al. 1996; Gohn et al. 2006) and Montagnais structures (Jansa et al. 1989) are among the most comprehensively documented by geophysical data and/or drilling (Fig. 1a).

Clearly, the assignment of a marine structure as an impact crater may be incorrect, particularly if the crater signature is incomplete due to erosion and redeposition of sediments, and in the absence of seismic profiles and drilling. Consequently, submarine crater proposals commonly attract charged discussions. In addition to the Malvinas structure case, typical examples are the Silverpit Structure in the epicontinental southern North Sea (Stuart and Allen 2002; Underhill 2004, 2009) and the Shiva Structure on the continental shelf west of India (Rampino and Haggerty 1996; Plummer 1998; Chatterjee et al. 2006). In contrast, the deep-water Eltanin impact event in the southeast Pacific Ocean, without any evidence of a crater-like feature, is a special case. It is yet the only proposed impact feature in deep water, mainly based on the content of piston cores which show iridium anomalies as well as melt fragments probably caused by a bolide impact in the $\sim 5$-km-deep ocean (Gersonde et al. 1997). Additionally, a deep-water impact may have caused seabed disturbance, erosion and mass wasting in the Central Arctic Ocean (Kristoffersen et al. 2008).

The need for unambiguous geological evidence, e.g., shatter cones, shock deformation/shock metamorphism features, and/or platinum group element enrichments to confirm a structure as an impact crater is well established (e.g., French and Koeberl 2010; Reimold et al. 2014). Seismic 2D/3D reflection data, and in cases seismic refraction data, are the most suitable geophysical data that provide sub-surface images and important structural constraints. However, an adequate number of publicly accessible seismic data exist only in a few confirmed or candidate impact structures. Nonetheless, non-seismic geophysical data are easier to acquire, especially in marine and remote terrestrial areas. Such data are normally the only source when discussing a potential impact crater, in particular onshore or marine gravity and magnetic profiles and/or maps. Additional geophysical data (e.g., electrical, 
electromagnetic) may also be used. A common practice is that potential field anomalies presented as profiles or grids together with other geophysical and/or morphological/structural observations are used to locate candidate impact structures. Subsequently, their origin is accounted for in a regional/semi-regional geological context (e.g., Vasconcelos et al. 2010), or the data are used to argue against debated structures (e.g., Müller et al. 2005). This process is only viable when one recognises that additional drilling/geological data are imperative to substantiate the impact origin. If only geophysical data are available, a wide range of geophysical datasets accompanied by proper modelling is required for the candidate structure to be widely accepted as a possible or probable (depending on the supporting evidence) impact crater, still pending drilling/field geological final confirmation. In our perception, no particular workflow template has yet been established for geophysical data to support, during an initial study stage, the potential impact origin of a candidate structure.

\section{MALVINAS STRUCTURE}

The entirely buried structure, northwest of West Falkland Island, has no topographic expression on the 250-450 $\mathrm{m}$ deep sea floor. The interpretation of a large eroded and buried impact crater arrives from a $\sim 250-\mathrm{km}$-diameter basin feature observed in seismic reflection profiles, of which only a short line segment is shown (Rocca et al. 2017). A major unconformity separates the $\sim 3-\mathrm{km}$-thick basin of probable Mesozoic-Tertiary sediments from folded and block-faulted rocks of probable Paleozoic age. Potential field data support the crater interpretation according to Rocca et al. (2017) who interpreted the impact to have occurred in Late Paleozoic, perhaps Permian. The Bouguer gravity field exhibits a $-30.6 \mathrm{mGal}$ negative anomaly over the basin centre, rimmed by a $250-\mathrm{km}$-diameter-wide circular ring of positive gravity anomalies reaching $+47.6 \mathrm{mGal}$. The magnetic field is interpreted as a series of circular positive magnetic anomalies, comprising a 'rose'-like circular total intensity magnetic anomaly of up to $214 \mathrm{nT}$ that corresponds to the positive circular gravity anomaly. Rocca et al. (2017) claimed that the magnetic anomaly is unique for the entire South Atlantic Ocean, and that both the gravity and magnetic signatures are compatible with that of the multi-ring Chicxulub impact structure. On the other hand, the presented magnetic map reveals a series of other circular and elongate anomalies on the Malvinas Plateau. Southeast of Falkland Island some of these anomalies appear to correspond to a positive gravity anomaly. 
Notably, the magnetic anomalies are more complex without the characteristic central positive anomaly observed in other large impact structures (Pilkington and Grieve 1992; Gulick et al. 2013). Furthermore, the Malvinas structure to the west of the West Malvinas Island lies on 34-km-thick continental crust in a region surrounded by volcanic margins to the east and southeast of the islands (Barker 1999), as well as off Argentina and southern Africa (Schimschal and Jokat 2018). We note that igneous intrusions such as dikes, sills and seaward dipping reflectors may occur within and on top of adjacent continental crust in volcanic margin settings (Eldholm and Coffin 2000; Eldholm et al. 2000).

Rocca et al. (2017) interpreted the potential field anomalies as reflecting a large, eroded impact structure with an infill of lower density post-impact sediments in the crater depression. The low infill density is ascribed to the fragmentation and redistribution of the target rocks, as well as shock-induced fracturing processes that will lower the porosity and thus the rock density (e.g., Tsikalas et al. 1999; Morgan et al. 2016; Christeson et al. 2018). However, Rocca et al. (2017) did not consider alternative models that may fit the observed geophysical anomalies such as a large volcanic centre, or intrusive activity that are also viable interpretations of the geophysical data.

If documentation by seismic profiles and drilling were to prove the impact origin of the Malvinas structure, it would be among the Earth's largest submarine as well as terrestrial impact craters (Earth Impact Database 2018). However, several issues have led to the present discourse and potential misinterpretations (McCarthy et al. 2017; Rampino et al. 2017; Reimold et al. 2017). Among these are: 1) technical aspects of the data presentation; 2) lack of a regional grid of geophysical data; and more importantly, 3) absence of comprehensive geophysical modelling to properly corroborate or reject alternative geologically/tectonically sound interpretations. Of course, such models should be consistent with accepted impact cratering processes.

\section{MJØLNIR CRATER}

The buried 40-km-diameter Mjølnir Structure in the Barents Sea (Fig. 1b) was first mapped and proposed as an impact crater by Gudlaugsson (1993) based on geophysical signature, 
seismic profiles, and geological setting. Subsequently, additional geophysical data and two shallow boreholes became available. One hole 30-km-away from the crater periphery (7430/10-U-01) was drilled in 1988. The other, the Mjølnir Crater core (7329/03-U-01) drilled in 1998, was dedicated to retrieve impact-derived sequences at the structure's centre (Fig. 1b). The subsequent studies have unequivocally confirmed the Mjølnir impact origin and resulted in a series of papers (e.g., Dypvik et al. 2010) describing the morphology, dimensions, sub-seafloor character, age, and impactor for this exceptionally well-preserved crater (Tsikalas et al. 1998a-c, 1999). Among the most important scientific features is the temporal correlation between the crater and the well-preserved ejecta layer found in Barents Sea shallow boreholes and onshore in Svalbard (e.g., Smelror et al. 2001; Tsikalas et al. 2002b; Dypvik et al. 2010).

The impact occurred on the sedimentary Bjarmeland Platform at a paleo-water depth of 300$400 \mathrm{~m}$ when the platform contained upper Paleozoic sediments, predominantly carbonates and evaporates below a 4-5-km-thick layer of Mesozoic siliciclastic marine sediments (Gudlaugsson et al. 1998). The structure, shown by seismic profiles, consists of an 8-kmdiameter central high, a 4-km-wide annular basin, and a 12-km-wide outer zone. There is a clear spatial correspondence between the radially zoned seismic structure and the potential field and traveltime/velocity anomalies (Fig. 2). The residual free-air shipborne gravity field shows a distinct 14-km-wide circular anomaly reaching $+2.5 \mathrm{mGal}$ over the central high, surrounded by a $45-\mathrm{km}$-diameter low reaching $-1.5 \mathrm{mGal}$ towards the periphery. The structural central high is located slightly offset relative to the gravity anomaly high.

Both shipborne and airborne magnetic data show that the residual anomaly ranges from -75 $\mathrm{nT}$ in the annular basin and outer zone to $20 \mathrm{nT}$ over the central high (Tsikalas et al. 1998a, $2010 b)$. Furthermore, there is a central, pull-up traveltime velocity anomaly of $\sim 80 \mathrm{~ms}$. The shallow boreholes confirmed the impact origin of the structure with brecciated sediments and a proximal ejecta layer with significant iridium enrichment and shocked quartz grains (Dypvik et al. 1996, 2010). The biostratigraphic age is considered a minimum impact age within the earliest Berriasian stage (Volgian-Ryazanian boundary in the Boreal/Arctic region) (Smelror et al. 2001; Tsikalas et al. 2002b). Based initially on empirical relations and later on numerical simulations a series of studies have associated the Mjølnir morphological, structural and sedimentological characteristics with the projectile impactor diameter, mass 
and energy, as well as the ejecta layer distribution around the impact site (Tsikalas et al. 1998b; Shuvalov et al. 2002, 2010). The impact also triggered an earthquake and a farreaching tsunami (Glimsdal et al., 2007). Furthermore, a plethora of studies utilising the available datasets have revealed details of the impact direction and angle, the presence of erosional resurge gullies in the structure's immediate vicinity, and accounted for the observed extensive post-impact deformation (e.g., Tsikalas 2005; Tsikalas and Faleide 2004, 2007; Gabrielsen et al. 2010).

\section{MJØLNIR CRATER STUDIES: A TEMPLATE FOR GEOPHYSICAL DATA INTEGRATION AND MODELLING}

Globally, the Mjølnir Crater is one of the few impact craters where a large amount of geophysical data (Table 1) have been dedicated to the study of the crater structure, associated cratering processes and post-impact deformation features. In fact, incompatibility with alternative non-impact interpretations was demonstrated by detailed modelling (Tsikalas et al. 1998a, 2010a). Because drilling subsequently confirmed the impact origin, the systematic Mjølnir workflow might apply as a template for the investigation of potential impact structures elsewhere. In the case of a candidate marine impact structure in a sedimentary target, one needs to evaluate, both qualitatively and quantitatively, whether processes other than impact could have formed the structure. Thus, alternative geologically/tectonically sound

non-impact interpretations that initially appear consistent with observations need to be discussed and effectively discounted by evidence. If excluding potential non-impact origins, further comprehensive geophysical analysis is required to support and decipher the impact related processes.

\subsection{Non-impact origin}

Alternative non-impact processes mainly include clay and salt diapirism and igneous, extrusive or intrusive, emplacement features. Other, less common processes comprise: salt withdrawal at depth (Underhill 2004); karstification/dissolution collapse structures; intrusioninduced fracturing (Underhill 2009); hydrothermal venting (Orti et al. 2008); and volcanic and large igneous province processes, including caldera forming processes and collapse following a volcanic eruption (Branney 1995), hot spot/plume volcanism, and volcanic rifted 
margin processes. All above processes can lead to mimicking several of the structural and morphological features expected for impact craters, i.e. concentric impact horizon morphology, annular fault and fracture patterns, and occurrence of a central peak.

Several signatures from non-impact features may appear compatible with those of impact processes. For example, a non-active clay diapir may reproduce, depending on the lateral physical property contrasts of the surrounding strata, and mimic circular gravity and traveltime/velocity anomalies. Possibly, clay diapirism may also induce extensive deformation above the structure due to differential compaction. Furthermore, regional features of clay diapirism include geodynamic environments characterized by overpressures, commonly induced either by rapid deposition of fine-grained siliciclastic sediments or by compression. In the case of salt diapirism, the main compatible regional signature includes proximity to a salt diapir basin/province. Commonly, a shallow thin salt body/canopy/overhang extends over the entire circumference of the proposed structure. Also, a prominent dense central "cap-rock" could easily reproduce local circular gravity and traveltime/velocity anomalies. However, the presence of a salt layer should be clearly imaged in seismic reflection profiles. Finally, an igneous feature is supported by the proximity to an igneous province and suitable emplacement age constraints. Alternative geometric configurations of volcanic features, and basaltic and granitic intrusions, need to be tested and resolved whether they locally image the circular structural and geophysical anomalies.

Detailed geophysical modelling is required to substantiate non-impact origins, in cases excluding a candidate impact structure. Several incompatible signatures relate to the nonimpact origin and processes. For active clay diapirism, these include the presence of a central positive gravity anomaly and the apparent lack of a negative velocity anomaly with a corresponding pull-down effect beneath the structure. A major incompatibility is that clay diapirs almost always form in clusters. The latter indicates that it is difficult to find a plausible mechanism for clay diapirism or any structural or depositional anomaly that might have initiated the formation of an isolated shale diapir. Other incompatible signatures are associated with salt diapirism. In geophysical modelling, the geometric fit of a number of plausible diapir structures with a significant stem may reproduce local parts of the observed anomalies (central gravity anomaly and annular gravity low); however, they may differ significantly in amplitude and shape both over the diapir proper and in the periphery. Finally, 
the observed seismic disturbance within an impact structure is incompatible with observations in typical rim-synclines or major salt-withdrawal sag. Other incompatible signatures relate to igneous (extrusive or intrusive) features. These mainly include the non-proximity to an igneous province and discordant emplacement age. In the case of a doleritic intrusion, the magnitude of the central magnetic anomalies is several hundred nT.

\subsection{Impact origin}

Depending on the available data, a comprehensive geophysical modelling workflow includes $2 \mathrm{D}, 2.5 \mathrm{D}$ or $3 \mathrm{D}$ modelling. As circularity is a common feature of candidate impact structures, $2.5 \mathrm{D}$ or pseudo-3D modelling procedures are preferred. In this case, symmetrical bodies with cross-sectional lengths commensurate with the seismically imaged structure at depth determine the initial model. Modelling can be performed on the actual anomalies, but the most effective procedure is using residual anomalies. Thus, regional effects are removed from the anomalies and the corresponding regional structural model. At Mjølnir, the depthconverted seismic interpretation shows that the structure is embedded in a platform sequence tilted slightly towards south. Removal of the regional trend allowed us to consider the geophysical anomalies and structural geometries as residual anomalies and residual structural model, respectively (Fig. 2; Table 2). Thus, only the disturbed region is modelled and the physical properties are all relative to the adjacent platform. This geometry provides an initial common geometry for the gravity, magnetic and traveltime/velocity modelling (Fig. 3).

Gravity modelling is performed either on Bouguer or free-air anomalies. It starts with a simple model where initially, the entire seismic disturbance or, in the absence of seismic profiles, the subsurface area is modelled with a uniform density contrast. Depending on the fit to the observed anomaly and geologic reasoning, the complexity of the model is increased in discrete steps. The impact-induced brecciation and increase in porosity causes a residual gravity anomaly low that commonly extends to or slightly beyond the crater rim (e.g., Grieve and Pesonen 1992; Pilkington and Grieve 1992). Furthermore, large complex craters (diameter $>30 \mathrm{~km}$ ) commonly exhibit a central gravity positive high ascribed to structural uplift during the upward displacement of deeper and denser strata to shallower levels during rebound of the crater floor and gravitational collapse (e.g., Melosh 1989; Espindola et al. 1995; Turtle et al. 2005). At Mjølnir, the observed structural uplift is in the order of $1.5-2 \mathrm{~km}$, within a possible range of 1-6 km predicted from empirical relations (Tsikalas et al. 1998b). 
The initial model also included the thickness of the allochthonous breccia determined to $\sim 1.0$ $1.3 \mathrm{~km}$ based on seismic images and morphometric calculations (Tsikalas et al. 1998b, 1999).

According to Pilkington and Grieve (1992), structures the size of Mjølnir and Malvinas should yield annular lows of about -7 mGal and -30 mGal, respectively. The observed Mjølnir value of $-1.5 \mathrm{mGal}$ is within their -1 to $-11 \mathrm{mGal}$ annular low range (Table 2). For the Malvinas structure the observed $-30.6 \mathrm{mGal}$ value is within the -9 to $-32 \mathrm{mGal}$ range. Thus, the larger Malvinas structure approximates the upper limit established by empirical scaling relationships (Pilkington and Grieve 1992). Similarly, it approximates the -30 mGal annular gravity low observed at the similar-size Chicxulub Crater (Pilkington et al. 1994), as noted by Rampino et al. (2017). However, the maximum annular gravity low of the Malvinas structure, as it is practice for confirmed impact craters, has to be defined relative to the level of the surrounding circular ring of positive gravity anomalies $(+47.6 \mathrm{mGal})$ and not only relative to the central negative anomaly (-30.6 mGal) (Rocca et al. 2017). Accordingly, the maximum negative gravity low becomes $-72.8 \mathrm{mGal}$; a value that contradicts all existing impact crater compilations and established scaling relationships (e.g., Pilkington and Grieve 1992), and is not consistent with Malvinas being an impact structure. Also, it again demonstrates the need both for a more rigorous treatment of the observations and for geophysical modelling.

At Mjølnir, the moderate gravity signature is ascribed to several combined effects, applicable to candidate impact structures in general. Primarily, the counteracting processes of brecciation and structural uplift determine the final density distribution within the impact-affected rock volume. Hence, less pervasive brecciation in relatively soft sediments may contribute to a smaller amplitude gravity low (Pilkington et al. 1995). Subsequently, the impact cratering processes are followed by lesser, long-term alteration due to differential compaction of postimpact sediments (Tsikalas et al. 2002b; Tsikalas and Faleide, 2007), which may reduce the density contrast between the crater periphery and platform, thus decreasing the amplitude of the annular gravity low. It is important to note that $\sim 1.5-2 \mathrm{~km}$ of the Mjølnir post-impact sediments have been eroded during late Cenozoic (e.g., Nyland et al. 1992; Baig et al. 2016) (Fig. 4). The interactive gravity modelling is continued until a satisfactory fit to the observed values is obtained. Consequently, we infer that the Mjølnir gravity field is consistent with the geometry as well as the lateral density distribution of an impact feature (Figs. 3 and 4). 
The magnetic signature of impact craters is variable. Most common is a broad magnetic low, primarily observed in crystalline target impacts, resulting from disturbance of regional magnetic trends. The amount of melt generated by impacts into sedimentary targets is expected to be comparable to that generated in crystalline target rocks, but with a more dispersed and scattered (i.e. polymictic suevitic breccias) rather than the coherent character in compact melt bodies or sheets (e.g., Stöffler et al. 1977; Kieffer and Simonds 1980; Cintala and Grieve 1994). However, even dispersed melt clasts may be magnetized during cooling, and have the potential to produce local magnetic anomalies. Estimates of magnetic source depths by half-slope depth methods (Tsikalas et al. 1998a) at the local Mjølnir anomalies yield a depth range of 1.6-3.4 km with an average value of $2.1 \mathrm{~km}$ (Fig. 3). These estimates clearly indicate shallow sources within the seismically disturbed region, rather than deep basement sources. Magnetic susceptibilities in the Mjølnir Crater core (7329/03-U-01, Fig. 1b) reaches $200 \times 10^{-3}$ SI, i.e. normal values for marine sedimentary rocks (Dypvik et al. 2010). The magnetic model accounts for the suppressed magnetic signature at the centre and generates magnetic anomalies over the annular basin that is within the observed $\pm 100 \mathrm{nT}$ range (Table 2), although exhibiting somewhat steeper gradients. A common feature of both the shipborne- and aeromagnetic surveys is the low amplitude of any observed magnetic anomaly within Mjølnir (e.g., Tsikalas et al. 2010b). We ascribe the low amplitude to the absence of shallow impact-related macroscopic melt bodies, a fact supported by the seismic images. Possibly, caused by dislocation of weakly magnetized platform strata associated with local concentrations of dispersed melts or minor melt dikes in the peripheral region.

Fracturing and brecciation will induce changes in the seismic velocity (Pilkington and Grieve 1992). If only 2D seismic reflection data are available, actual velocity anomalies would cause pull-up or pull-down effects on continuous reflectors below the impact structure. If we assume that such reflectors are approximately planar, even small velocity anomalies may yield local reflector relief. In 3D seismic data, the stacking velocities will show a disturbance caused by the impact structure, and relevant depth imaging and full waveform inversions may better visualise impact structure features (e.g. Morgan et al. 2016). At Mjølnir, analysis of the dense grid of utilised 2D seismic data reveals a 16-km-diameter traveltime anomaly that rises +80 ms beneath the central high, decreasing towards the annular basin (Fig. 3; Table 2). The average velocity between the top of the structure and the top Permian level is estimated to 4.0 $\mathrm{km} / \mathrm{s}$, corresponding to a density of $2.39 \mathrm{~g} / \mathrm{cm}^{3}$ (Barton 1986; Tsikalas et al. 2010b). Similarly, 
the modelled density anomalies correspond to velocity anomalies from +175 to $-200 \mathrm{~m} / \mathrm{s}$ (Fig. 4). The calculated traveltime anomaly approximates the observed relief of the top Permian reflector, especially in the centre. Thus, the traveltime/velocity anomaly is closely related to the lateral density distribution within the structure induced by the impact cratering processes (Fig. 3).

\section{DISCUSSION}

\subsection{Malvinas structure versus Mjølnir Crater}

Criticism about the data presentation and interpretation by Rocca et al. (2017) has triggered debate. In particular, Reimold et al. (2017) disagreed that the seismic interpretation was compatible with a large eroded and buried Late Paleozoic impact basin. They also challenged the contention of the similarity of Malvinas gravity and magnetic anomalies with those over the Chicxulub Crater. The other, highly sceptical, commentary by McCarthy et al. (2017) challenged both the presentation and the interpretation of the single seismic profile interpreted by Rocca et al. (2017) by analysing it in a regional geologic setting. They concluded that the seismic profile did not corroborate a crater hypothesis; nor did the presented potential field anomalies. They also challenged the circularity of the gravity anomaly and noted that the magnetic 'rose-like' anomaly may as well originate from a volcanic intrusive complex. Rampino et al. (2017) addressed the above criticism stressing that the potential field anomalies were the main 'evidence' for an impact crater structure by their similarity with those at the Chicxulub Crater, as well as numerous other craters worldwide. In particular, they claimed that the negative, circular residual gravity anomaly can be replicated by fracturing and brecciation of the target rocks and/or less dense sediment crater infill; and that an $8 \mathrm{~km}$ fracture depth will produce a maximum anomaly of $-33 \mathrm{mGal}$. Moreover, they noted that impact craters with diameter $>40 \mathrm{~km}$ commonly yield a central positive magnetic anomaly induced by re-magnetization of the target rocks.

A confirmed buried impact crater depends critically on detailed seismic reflection mapping, and on drilling information. We consider the contention of circular geological and geophysical impact features as ambiguous without modelling along seismic profiles, including alternative non-impact origin models. In fact, no alternative geological features 
were considered for the Malvinas structure by Rocca et al. (2017) and Rampino et al. (2017). In particular, spatial correspondence of structural features and geophysical anomalies is required to substantiate any impact interpretation (Figs. 3 and 4). Nonetheless, in the absence of geological data and adequate seismic profiles, the available potential field anomalies must be considered and meticulous care applied in analysis and presentation. Thus, we find that the impact evidence for the Malvinas structure is insufficient because of the technical quality in data presentation, and most importantly, in the absence of systematic geophysical modelling. In addition, the type (actual or residual) of potential field anomalies is unclear, and the removal of regional trends would have enhanced the candidate structure. We also note that the reference level (datum) of the maximum negative gravity low is critical in order to avoid misinterpretations. When properly defining the maximum annular gravity low relative to the surrounding ring of positive anomalies, the result is an unprecedented gravity low that contradicts the reported value by Rocca et al. (2017) and Rampino et al. (2017). Thus, we find it not compelling to accept that the Malvinas structure is of an impact origin.

Although the Malvinas structure is proposed as a large-size impact structure and compared to the similarly sized Chicxulub Crater, a reference to the studies of the medium-size $40-\mathrm{km}$ diameter Mjølnir Crater could, in our opinion, indeed have been beneficial (Figs. 3 and 4; Table 2). These show, in particular, that the integrated analysis of seismic and potential field data is crucial for any interpretation of a marine impact crater without drilling data. Moreover, an important component of the evaluation process is the quantitative analysis and potential rejection, through geophysical modelling, of alternative non-impact models. We suggest that the Mjølnir work provides a methodology that applies to future studies of the Malvinas structure possibly including available industry 2D seismic profiles (e.g., Jablonski 2018), as well as to proposed marine impact craters in general.

\subsection{Modelling-based workflow template for proposed marine impact craters}

Statistical predictions indicate that there is a large number of yet-to-find impact craters on Earth (Stewart 2011), with the great majority in marine areas and in sedimentary targets. The Malvinas structure discourse and earlier debated impact-origin structures have revealed the need to establish an impact crater diagnostic workflow template. We, therefore, present a generic flow diagram applicable to candidate impact structures based on the workflow at Mjølnir (Fig. 5). The workflow template is divided into two main processes, namely A and B 
(Fig. 5), when only geophysical data are available (common situation) and when drilling samples/geological data are or become available at a later stage, respectively, following the evaluation of geophysical data.

The iterative template utilises all available data and includes a series of successive steps. If geological/drilling data exist, these may provide the 'ground-truth' to confirm or reject any impact hypothesis. Thus, analyses of outcrop or borehole samples together with regional geological data will be compared against the checklist of established unambiguous impact geologic evidence (e.g., French and Koeberl 2010; Reimold et al. 2014). The objective is to avoid possible pitfalls or misinterpretations (e.g., Reimold 2007; Melosh 2017). This process (B, Fig. 5) concludes with a geological model for the structure's origin.

Availability of geologic and borehole data is the exception for the majority of proposed impact structures. In the absence of drilling information, seismic data and potential field data supported by modelling provide the most reliable means to decipher the origin of candidate impact structures (A, Fig. 5). All available geophysical data need to be utilised (A1, Fig. 5). A close integration of seismic interpretation, when feasible, and regional considerations might reduce the inherit non-uniqueness in potential field modelling. This can provide a powerful tool to discriminate impact structures from other natural geological features. Initially, the template evaluates, both qualitatively and quantitatively, whether processes other than impact could have formed the structure. It includes a range of alternative non-impact models that provide a realistic fit to the data that have to be discussed and accounted for (A2, Fig. 5). The detailed geophysical interpretation and modelling may exclude alternative models. Unbiased comprehensive geologic reasoning is a prerequisite when counter-arguing, through modelling and additional observations, against alternative non-impact origins.

After excluding potential non-impact origins, additional geophysical modelling may be required to support and decipher the impact related processes. Initially, the modelling effort is devoted to substantiate the impact origin by modelling changes in physical properties caused by the impact (A3, Fig. 5). A close spatial correspondence of the structure and potential field anomalies is required to establish a causal relationship. In this respect, an initial simple gravity-magnetic-velocity model needs to constrain the large-scale impact structural geometries. If successful, further physical properties modelling such as porosity-density- 
velocity and post-impact deformation can be performed. Similarly, integration of more complexity in the model may yield information on the impact cratering processes, and potentially resolve geophysical/morphological/structural ambiguities (A4, Fig. 5). The end result is a classification and bona fide confirmation of the structure as a possible or probable impact structure. The same workflow template could also, with minor adaptions, be applied to non-marine impact structure candidates. Nonetheless, the final verification is contingent on ground-truth geological data (B, Fig. 5).

\section{CONCLUSIONS}

The well-documented Mjølnir Crater in the Barents Sea is discussed in the context of the ambiguous nature of the recently proposed, and debated, impact crater at the Malvinas (Falkland Plateau) in the South Atlantic. The Malvinas structure discourse and that of other debated impact-origin structures reveal the need for a diagnostic geophysical-based template, supported by modelling. This template can be used during an initial study, or in combination with geological data when proposing a marine impact structure.

When comparing the Malvinas structure with the Mjølnir Crater we find that the evidence for the Malvinas structure as an impact crater is far from convincing because of: 1) technical aspects in data presentation; 2) poor clarity in the type (actual or residual) of the potential field anomalies; 3 ) the fact that removal of regional trends would have clarified the candidate structure; and 4) most importantly, the absence of systematic geophysical modelling. The latter led to not properly discounting alternative geologically/tectonically sound interpretations prior to the impact crater proposal for the Malvinas structure. In addition, an initial comparison of the observed geophysical anomalies shows that the Malvinas structure is not compatible with global impact crater compilations (e.g., Pilkington and Grieve 1992). For example, the observed maximum annular gravity low relative to the level of the surrounding circular ring of positive gravity anomalies is $-72.8 \mathrm{mGal}$. Despite their different sizes, the comparison of the Malvinas structure and Mjølnir Crater shows the ambiguous nature of the Malvinas structure and that the integrated analysis of seismic and potential field data is crucial for any interpretation of a marine impact crater without drilling data. 
Availability of geological and borehole data is the exception for the majority of proposed impact structures. In the absence of drilling information, seismic and potential field data provide the most reliable source of information. Based on the Mjølnir work, an expanded workflow template is suggested for the analysis of a proposed candidate structure. A close integration with seismic profiles and regional considerations are able to reduce, both qualitatively and quantitatively, the inherited non-uniqueness in potential field modelling. This provides a powerful tool to discriminate impact structures from other geological features. Initially, a range of alternative non-impact interpretations need to be discussed, and detailed geophysical interpretation and modelling is required to exclude those. Subsequently, further iterative geophysical modelling is required to support and decipher the impact related processes, and to obtain a close spatial correspondence of the modelled structure with potential field anomalies. Additional complexity (a more complex model with additional impact structure features) in the crater model can be introduced by physical properties modelling of porosity-density-velocity and post-impact deformation relationships.

With the current evidence, the Malvinas structure is unlikely to be an impact crater. Final impact confirmation of the Malvinas structure will await unambiguous geological evidence. We suggest that the diagnostic workflow template in Fig. 5 provides a methodology to be applied in future studies of the Malvinas structure, as well as proposed marine impact craters in general. The same workflow template could also, with minor adaptions, be applied to nonmarine impact structure candidates.

\section{ACKNOWLEDGEMENTS}

We are grateful to the many participants involved in the Mjølnir impact crater research, in particular to Steinar Thór Gudlaugsson who first proposed it to be an impact crater and Jan Inge Faleide for his important contribution. We thank reviewers A. Crosta and S. Gulick, as well as Associate Editor M. Poelchau for their constructive comments and suggestions. 


\section{REFERENCES}

Baig I., Faleide, J. I., Jahren J., and Mondol N. H. 2016. Cenozoic exhumation on the southwestern Barents Shelf: Estimates and uncertainties constrained from compaction and thermal maturity analyses. Marine and Petroleum Geology 73: 105-130.

Barker P. F. 1999. Evidence for a volcanic rifted margin and oceanic crustal structure for the Falkland Plateau Basin. Journal of the Geological Society London 156: 889-900.

Barton P. J. 1986. The relationship between seismic velocity and density in the continental crust - a useful constraint? Geophysical Journal International 87: 195-208.

Branney M. J. 1995. Downsag and extension at calderas: new perspectives on collapse geometries from ice-melt, mining, and volcanic subsidence. Bulletin of Volcanology 57: 303-318.

Chatterjee S., Guven N., Yoshinobu A., and Donofrio R. 2006. Shiva structure: a possible KT boundary impact crater on the western shelf of India. Special Publications Museum Texas Tech University 50: 39 pp.

Christeson, G. L., Gulick, S. P. S., Morgan, J. V. and 34 others 2018. Extraordinary rocks from the peak ring of the Chicxulub impact crater: P-wave velocity, density, and porosity measurements from IODP/ICDP Expedition 364. Earth and Planetary Science Letters 495: $1-11$.

Cintala M. J. and Grieve R. A. F. 1994. The effects of differential scaling of impact melt and crater dimensions on lunar and terrestrial craters: Some brief examples. In Large meteorite impacts and planetary evolution, edited by Dressler B. O., Grieve R. A. F. and Sharpton V. L. GSA Special Paper \#293. Boulder, Colorado: Geological Society, pp. 51-59.

Dypvik H., Gudlaugsson S. T., Tsikalas F., Attrep F., Ferrell R. E., Krinsley D. H., and Nagy J. 1996. Mjølnir Structure: An impact crater in the Barents Sea. Geology 24: 779-782.

Dypvik H., Tsikalas F., and Smelror, M. (eds.) 2010. The Mjølnir Impact event and its consequences. Springer-Verlag, Berlin, $318 \mathrm{pp}$.

Earth Impact Database 2018. http://www.passc.net/EarthImpactDatabase/Index.html

Eldholm O. and Coffin M. F. 2000. Large Igneous Provinces and Plate Tectonics. In The History and Dynamics of Global Plate Motion, edited by Richards M., Gordon R., and van der Hilst R., American Geophysical Union. Geophysical Monograph Series 121: 309-326.

Eldholm O., Gladczenko T. P., Skogseid J., and Planke S., 2000. Atlantic volcanic margins: a comparative study. Geological Society, London, Special Publications 167: 411-428.

Espindola J. M., Mena M., de La Fuente M., and Campos-Enriquez J. O. 1995. A model of the Chicxulub impact structure (Yucatan, Mexico) based on its gravity and magnetic signatures. Physics of the Earth and Planetary Interiors 92: 271-278.

French B. M. and Koeberl C. 2010. The convincing identification of terrestrial meteorite impact structures: What works, what doesn't, and why. Earth Science Reviews 98: 123170.

Gabrielsen R. H., Dypvik H., and Shuvalov V. 2010. Chapter 8. Structural Analysis of Deformed Central Peak Sediments. In The Mjolnir Impact event and its consequences, edited by Dypvik H., Tsikalas F., and Smelror M. Springer-Verlag, Berlin, pp. 211-228.

Gersonde R., Kyte F. T., Bleil U., Diekmann B., Flores J. A., Gohl K., Grahl G., Hagen R., Kuhn G., Sierro F. J., Völker D., Abelmann A, and Bostwick J. A. 1997. Geological record and reconstruction of the late Pliocene impact of the Eltanin asteroid in the Southern Ocean. Nature 390: 357-363.

Glimsdal S., Pedersen G. K., Langtangen H. P., Shuvalov V., and Dypvik H. 2007. Tsunami generation and propagation from the Mjølnir asteroid impact. Meteoritics \& Planetary Science 42: 1473-1493. 
Grieve R. A. F. and Pesonen L. J. 1992. The terrestrial impact record. Tectonophysics 216: 130.

Gohn G. S., Koeberl C., Miller K. G., Reimold, W. U., Cockell C. S., Horton J. W., Sanford W. E. and Voytek M. A. 2006. Chesapeake impact structure drilled. Eos 87: 349-360.

Gudlaugsson S. T. 1993. Large impact crater in the Barents Sea. Geology 21: 773-777.

Gudlaugsson S. T., Faleide J. I., Johansen S. E., Breivik A. J. 1998. Late Palaeozoic structural development of the south-western Barents Sea. Marine and Petroleum Geology 15: 73102.

Gulick S. P. S., Christeson G. L., Barton P. J., Grieve R. A. F., Morgan J. V. and UrrutiaFucugauchi J. 2013. Geophysical characterization of the Chicxulub impact crater. Review of Geophysics 51: 31-52.

Jablonski D. 2018. The Malvinas Basin: Revisiting Prospectivity. GEOExPro 15 (issue 2, May 2018): 32.

Jansa L. F., Pe-piper G., Robertson P. B., and Fridenreich O. 1989. Montagnais: A submarine impact structure on the Scotian Shelf, eastern Canada. Geological Society of America Bulletin 101: 450-463.

Kieffer S. W. and Simonds C. H. 1980. The role of volatiles and lithology in the impact cratering processes. Reviews of Geophysics 18: 143-181.

Koeberl C., Poag C. W., Reimold W. U., and Brandt D. 1996. Impact origin of the Chesapeake Bay structure and the source of the North American tektites. Science 271: 1263-1266.

Kring D. A., Claeys P., Gulick S. P. S., Morgan J. V., Collins G. S., and IODP-ICDP Expedition 364 Science Party (2016). Chicxulub and the exploration of large-peak ring impact craters through scientific drilling. GSA Today 27: 4-8.

Kristoffersen Y., Hall J. K., Hunkins K., Ardai J., Coakley B. J., and Hopper J. R. 2008. Extensive local seabed disturbance, erosion and mass wasting on Alpha Ridge, Central Arctic Ocean: possible evidence for an extra-terrestrial impact? Norwegian Journal of Geology 88: 313-320.

Ludwig J. W., Nafe J. E., and Drake C. L. 1970. Seismic refraction. In The sea, edited by Maxwell A. E. Wiley, New York: vol. 4, pp. 53-84.

McCarthy D., Aldiss D., Arsenikos, S., Stone, P., and Richards P. 2017. Comment on "Geophysical evidence for a large impact structure on the Falkland (Malvinas) Plateau". Terra Nova 29: 411-415.

Melosh H. J. 1989. Impact cratering: a geologic process. Oxford University Press \& Clarendon Press, Oxford, 245 pp.

Melosh H. J. 2017. Impact geologists, beware! Geophys. Res. Lett., 44, 8873-8874.

Morgan J. V., Gulick S. P. S., Bralower T. and 35 others 2016. The formation of peak rings in large impact craters. Science 354: 878-882.

Müller R. D., Goncharov A., and Kritski A. 2005. Geophysical evaluation of the enigmatic Bedout basement high, offshore northwestern Australia. Earth and Planetary Science Letters 237: 264-284.

Nyland B., Jensen L. N., Skagen J., Skarpnes P., and Vorren T. O. 1992. Tertiary uplift and erosion in the Barents Sea: Magnitude, timing, and consequences. In Structural and tectonic modeling and its application to the petroleum geology, edited by Larsen, R. M., Brekke, H., Larsen, B. T., and Tallerras, E. Norwegian Petroleum Society Special Publication 1: 153-162.

Orti L., Di Martino M., Morelli M., Cigolini C., Pandeli E., and Buzzigoli A. 2008. Nonimpact origin of the crater-like structures in the Gilf Kebir area (Egypt): Implication for the geology of eastern Sahara. Meteoritics \& Planetary Science 43: 1629-1639. 
Pilkington M. and Grieve R. A. F. 1992. The geophysical of terrestrial impact craters. Review of Geophysics 30: 161-181.

Pilkington M., Hildebrand A., and Ortiz-Aleman C. 1994. Gravity and magnetic field modelling and structure of the Chicxulub crater, Mexico. Journal of Geophysical Research 99: 13147-13162.

Pilkington M., Jansa L. F., and Grieve R. A. F. 1995. Geophysical studies of the Montagnais impact crater, Canada. Meteoritics 30: 446-450.

Plummer P. 1998. Seychelles geology and the Shiva impact crater theory. Phelsuma 6: 9-19.

Rampino M. R. 1992. A large Late Permian impact structure from the Falkland Plateau. Eos 73: 136.

Rampino M. R. and Haggerty, B.M. 1996. The "Shiva Hypothesis": Impacts, mass extinctions, and the galaxy. Earth, Moon, and Planets 72: 441-460.

Rampino M. R., Rocca, M. C. L., and Presser J. L. B. 2017. Reply to comments on "Geophysical evidence for a large impact structure on the Falkland (Malvinas) Plateau". Terra Nova 29: 412-419.

Reimold W. U. 2007. The impact crater bandwagon (some problems with the terrestrial impact cratering record). Meteoritics \& Planetary Science 42: 1467-1472.

Reimold W. U., Ferrière L., Deutsch A., and Koeberl, C. 2014. Impact controversies: Impact recognition criteria and related issues. Meteoritics \& Planetary Science 49: 723-731.

Reimold W. U., Crósta A. P., Koeberl C., and Hauser N. 2017. Comment on "Geophysical evidence for a large impact structure on the Falkland (Malvinas) Plateau". Terra Nova 29: 409-410.

Rocca M. C. L., Rampino M. R., and Presser, J. L. B. 2017. Geophysical evidence for a large impact structure on the Falkland (Malvinas) Plateau. Terra Nova 29: 233-237.

Schimschal C. M. and Jokat W. 2018. The continental structure of the continental margin east of the Falkland Islands. Tectonophysics 724: 234-253.

Shuvalov V., Dypvik H., and Tsikalas F. 2002. Numerical simulations of the Mjølnir marine impact crater. Journal of Geophysical Research 107: doi 10.1029/2001JE001698.

Shuvalov V., Dypvik H., and Tsikalas F. 2010. Chapter 7. The Impact Dynamics. In The Mjølnir Impact event and its consequences, edited by Dypvik H., Tsikalas F., and Smelror M. Springer-Verlag, Berlin, pp. 195-210.

Smelror M., Kelly S. R. A., Dypvik H., Mørk A., Nagy J., and Tsikalas F. 2001. Mjølnir (Barents Sea) meteorite impact offers a Volgian-Ryazanian boundary marker. Newsletters on Stratigraphy 38: 129-140.

Stewart S. A. 2011. Estimates of yet-to-find impact crater population on Earth. Journal of the Geological Society 168: 1-14.

Stuart S. A. and Allen P. J. 2002. A 20-km-diameter multi-ringed impact structure in the North Sea. Nature 418: 520-523.

Stöffler D., Ewald U., Ostertag R., and Reimold W. U. 1977. Research drilling Nördlingen 1973, Ries: composition and texture of polymictic impact breccias. Geol Bavarica 75: 163 190.

Telford W. M., Geldart L. P., and Sheriff R. E. 1990. Applied geophysics. Cambridge University Press, Cambridge, 770 pp.

Tsikalas F. 1997. A Geophysical Study of Mjølnir: a Proposed Impact Structure in the Barents Sea. Dr. Scient. (PhD) Dissertation, Univ. of Oslo, 102 pp.

Tsikalas F., Gudlaugsson S. T., Eldholm O., and Faleide J. I. 1998a. Integrated geophysical analysis supporting the impact origin of the Mjølnir structure, Barents Sea. Tectonophysics 289: $257-280$. 
Tsikalas F., Gudlaugsson S. T., and Faleide J. I. 1998b. The anatomy of a buried complex impact structure: the Mjølnir Structure, Barents Sea. Journal of Geophysical Research 103: 30469-30484.

Tsikalas F., Gudlaugsson S. T., and Faleide J. I. 1998c. Collapse, infilling, and postimpact deformation at the Mjølnir impact structure, Barents Sea. Geological Society of America Bulletin 110: 537-552.

Tsikalas F., Gudlaugsson S. T., Faleide J. I., and Eldholm O. 1999. The Mjølnir marine crater porosity anomaly. Deep-Sea Research II 49: 1103-1130.

Tsikalas F., Gudlaugsson S. T., Faleide J. I., and Eldholm O. 2002a. Mjølnir Structure; Barents Sea: a marine impact crater laboratory. In Large Meteorite Impacts and Planetary Evolution II, edited by Dressler B. and Sharpton V. L. Geological Society of America, Special Paper 339: 193-204.

Tsikalas F., Faleide J. I., Eldholm O., and Dypvik H. 2002b. Seismic correlation of the Mjølnir impact crater to shallow boreholes. In Impacts in Precambrian shields (Impact Studies), edited by Plado J. and Pesonen L. J. Springer-Verlag, Berlin-Heidelberg, pp. 307321.

Tsikalas F. and Faleide J. I. 2004. Nearfield erosional features at the Mjølnir impact crater: The role of marine sedimentary target. In Cratering in marine environments and on ice (Impact Studies), edited by Dypvik H., Burchell M., and Claeys P. Springer-Verlag, Berlin-Heidelberg, pp. 39-55.

Tsikalas F. 2005. Mjølnir Crater as a result of oblique impact: Asymmetry evidence constrains impact direction and angle. In Impact tectonism (Impact Studies), edited by Koeberl C., Henkel H. Springer-Verlag, Berlin-Heidelberg, pp 285-306.

Tsikalas F. and Faleide J. I. 2007. Postimpact structural crater modification due to sediment loading: An overlooked process. Meteoritics \& Planetary Science 42: 2013-2029.

Tsikalas F., Faleide J. I., Gudlaugsson S. T., and Eldholm O. 2010a. Chapter 3. Impact Structure and Morphology. In The Mjølnir Impact event and its consequences, edited by Dypvik H., Tsikalas F., and Smelror M. Springer-Verlag, Berlin, pp. 47-73.

Tsikalas F., Faleide J. I., Werner S., Torsvik T., Gudlaugsson S. T., and Eldholm O. 2010b. Chapter 4. Impact Geophysics and Modelling. In The Mjolnir Impact event and its consequences, edited by Dypvik H., Tsikalas F., and Smelror M. Springer-Verlag, Berlin, pp. 75-137.

Turtle E. P., Pierazzo E., Collins G. S., Osinski G. R., Melosh H. J., Morgan J. V., Reimold W. U. 2005. Impact structures: What does crater diameter mean? In Large meteorite impacts III, edited by Kenkmann T., Hörz F., and Deutsch A. GSA Special Paper \#384. Boulder, Colorado: Geological Society of America, pp 1-24.

Underhill J. R. 2004. Earth science: An alternative origin for the 'Silverpit crater'. Nature 428: 280.

Underhill J. R. 2009. Role of intrusion-induced salt mobility in controlling the formation of the enigmatic "Silverpit Crater", UK Southern North Sea. Petroleum Geoscience 15: 197216.

Vasconcelos M. A. R., Crósta A. P., and Molina E. C. 2010. Geophysical characteristics of four possible impact structures in the Parnaíba Basin, Brazil: Comparison and implications. In: Large Meteorite Impacts and Planetary Evolution IV, edited by Gibson R. L. and Reimold W. U. GSA Special Paper \#465. Boulder, Colorado: Geological Society of America, pp. 201-217. 


\section{TABLE CAPTIONS}

Table 1: Mjølnir studies geophysical data.

Table 2: Summary of Mjølnir Crater residual anomalies and corresponding modelled physical property anomalies.

\section{FIGURE CAPTIONS}

Figure 1: (a) Location of Mjølnir Crater and Malvinas structure (red dots), as well as all other recognized terrestrial and marine impact structures (black dots; from Earth Impact Database 2018); (b) regional setting of Mjølnir Crater in southwestern Barents Sea. Locations of the two shallow boreholes and profile A-A' in Figs. 3 and 4 (modified from Tsikalas et al. 1998b).

Figure 2: Residual Mjølnir impact geometry (a) (modified from Tsikalas 1997). Potential field (b, c) and traveltime/velocity (d) anomalies (modified from Tsikalas et al. 2010b). The view in the illuminated perspective images is from $30^{\circ}$ above the horizon looking northeast (azimuth $40^{\circ}$ ); light source at azimuth $290^{\circ}$.

Figure 3: Mjølnir potential field and traveltime/velocity modelling of seismic profile A-A' (Fig. 1b). The impact structure model has differentiated brecciation. The velocity-density conversions are based on empirical relations (e.g., Ludwig et al. 1970; Barton 1986). Magnetic susceptibilities are determined from typical rock properties (e.g., Telford et al. 1990). Magnetic source depth estimates refer to all shipborne magnetic profiles in Fig. 2c. In view of the circular structure, the depth estimates have been plotted according to distance from the centre. Circled depth estimates from profile A-A'. Density contrasts in $\mathrm{kg} / \mathrm{m}^{3}$. SF, seafloor; TD, impact horizon (top disturbance; the first continuous reflector above the seismic disturbance); TP, Top Permian (modified from Tsikalas et al. 2010b).

Figure 4: Mjølnir radially-varying physical property changes and deformation types. (a) Relative porosity anomaly models along type cross-section A-A' (Figs. 1b and 3). Shading denotes the change between the present and the decompacted porosity anomaly distributions. PR, peak ring (modified from Tsikalas et al. 1999). (b-d) Original crater, crater model geometry, and present crater, respectively. Abbreviations in Fig. 3. DZ, area of intensely 
disturbed seismic reflections; TZ, transitional area of less disturbance. Modelled impactinduced physical property changes (cf. Fig. 3): density contrasts in $\mathrm{kg} / \mathrm{m}^{3}$, seismic velocities in $\mathrm{m} / \mathrm{s}$, and porosity anomalies in \% (modified from Tsikalas and Faleide 2007).

Figure 5: Diagnostic workflow template for proposing a marine impact crater. A: workflow process and iterative steps (A1-A4; workflow starts at step A1) to be followed in the absence of drilling samples/geological data when only geophysical data are available; B: workflow process to be followed when drilling samples/geological data are initially available or became available at a later stage following the evaluation of geophysical data. 
Table 1.

\begin{tabular}{|c|c|c|c|}
\hline Data type & $\begin{array}{c}\text { Number of } \\
\text { profiles }\end{array}$ & $\begin{array}{c}\text { Profile length } \\
(\mathrm{km})\end{array}$ & $\begin{array}{c}\text { Record length } \\
\text { (s) }\end{array}$ \\
\hline \multicolumn{4}{|l|}{ Seismic } \\
\hline \multirow{5}{*}{$\begin{array}{l}\text { Conventional MCS } \\
\text { Shallow } \mathrm{MCS}^{2} \\
\text { Shallow } \mathrm{SCS}^{4} \\
\text { Shallow refraction (sonobuoys) } \\
\text { Side-scan sonar }\end{array}$} & 20 & 1,081 & $6-10$ \\
\hline & 4 & 174 & 2 \\
\hline & 23 & 872 & 1 \\
\hline & 16 & 48 & 2 \\
\hline & 4 & 174 & na \\
\hline Shipborne gravity (along $S C S)^{4}$ & 9 & 397 & na \\
\hline \multicolumn{4}{|l|}{ Magnetics } \\
\hline \multirow{2}{*}{$\begin{array}{l}\text { Shipborne (along SCS) } \\
\text { Airborne }^{5}\end{array}$} & 7 & 292 & na \\
\hline & 50 & 2,900 & na \\
\hline $\begin{array}{l}\text { Traveltime/velocity anomaly } \\
(\text { along } M C S)^{1,2,3}\end{array}$ & 20 & 1,081 & na \\
\hline
\end{tabular}

MCS: multi-channel seismic profiles; SCS: single-channel seismic profiles.

Data source: ${ }^{1}$ NPD: Norwegian Petroleum Directorate, Stavanger, Norway; ${ }^{2} I K U$ : IKU (now Sintef) Petroleum Research, Trondheim, Norway; ${ }^{3}$ BGR: Bundesanstalt für Geowissenschaften und Rohstoffe, Hannover,

Germany; ${ }^{4}$ FFI (Norwegian Defence Research Establishment, Horten, Norway; ${ }^{5}$ NGU (Geological Survey of Norway, Trondheim, Norway): proprietary data acquired in 2006 but not extensively used so far. 
Table 2.

\begin{tabular}{|l|c|c|}
\hline $\begin{array}{l}\text { Residual anomalies \& modelled } \\
\text { physical properties }\end{array}$ & Annular basin/periphery & Central part \\
\hline $\begin{array}{l}\text { Gravity anomaly }(\mathrm{mGal}): \text { observed } \\
\text { [range from crater compilations] }^{*}\end{array}$ & $-1.5[-7(\text { range }-1 \text { to }-11)]^{*}$ & $+2.5[+3.5(\text { range }+2 \text { to }+9)]^{*}$ \\
\hline Magnetic anomaly $(\mathrm{nT})^{1}$ & -50 to -75 & 0 to +20 \\
\hline Traveltime anomaly $(\mathrm{ms})^{2,3,4}$ & -10 to -20 & +80 \\
\hline Modelled density contrast $\left(\mathrm{kg} / \mathrm{m}^{3}\right)$ & -30 to -50 & +25 \\
\hline Modelled velocity anomaly $(\mathrm{m} / \mathrm{s})$ & -150 to -200 & +175 \\
\hline Modelled porosity anomaly $(\%)$ & +2.5 & -2.2 \\
\hline
\end{tabular}

*Ranges from Pilkington and Grieve (1992).

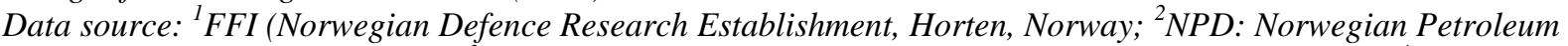
Directorate, Stavanger, Norway; ${ }^{3} I K U:$ IKU (now Sintef) Petroleum Research, Trondheim, Norway; ${ }^{4} B G R$ :

Bundesanstalt für Geowissenschaften und Rohstoffe, Hannover, Germany. 


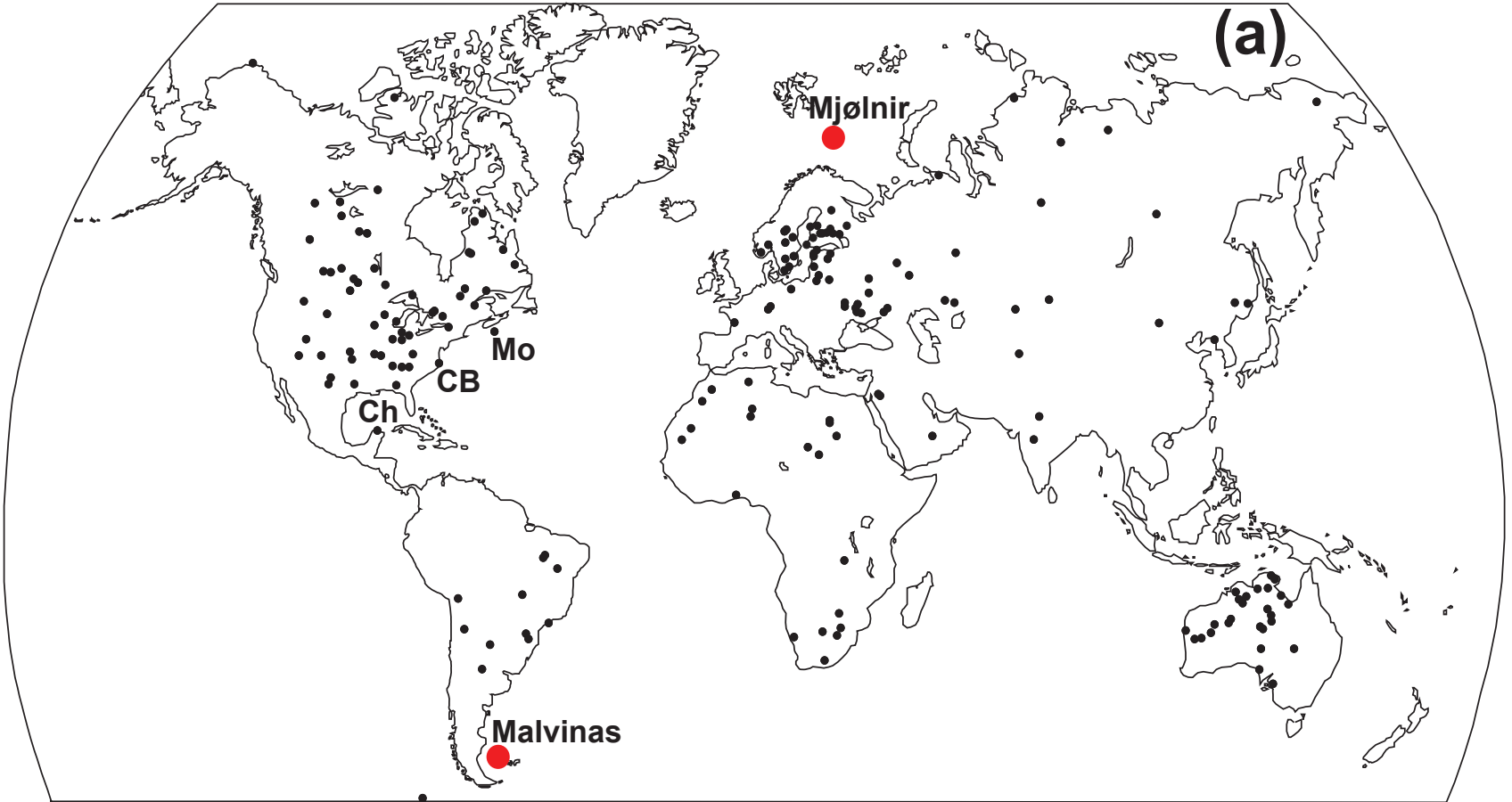

CB Chesapeake Bay Crater

Ch Chicxulub Crater

Mo Montagnais Crater

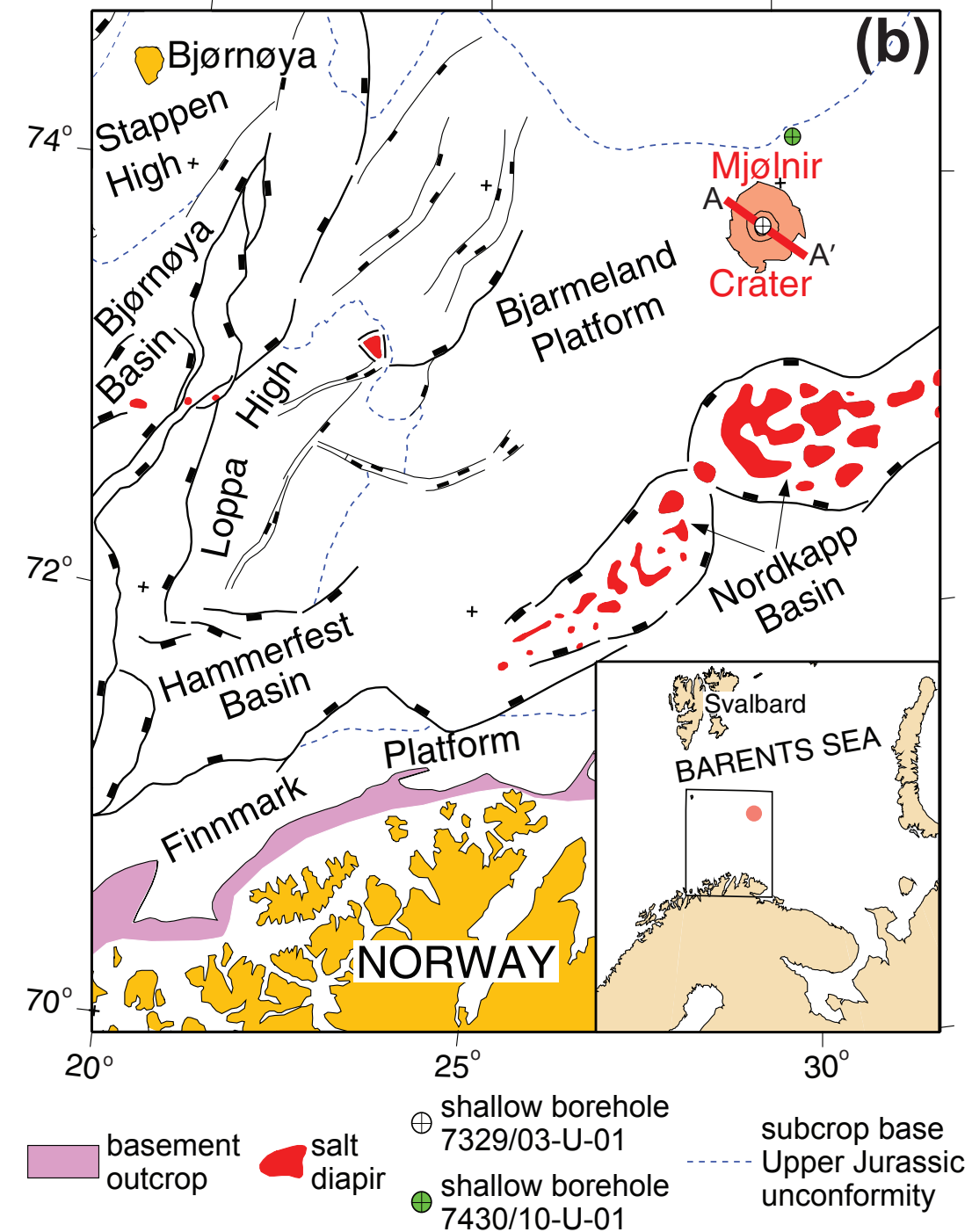

Figure 1 
(a) Residual impact geometry

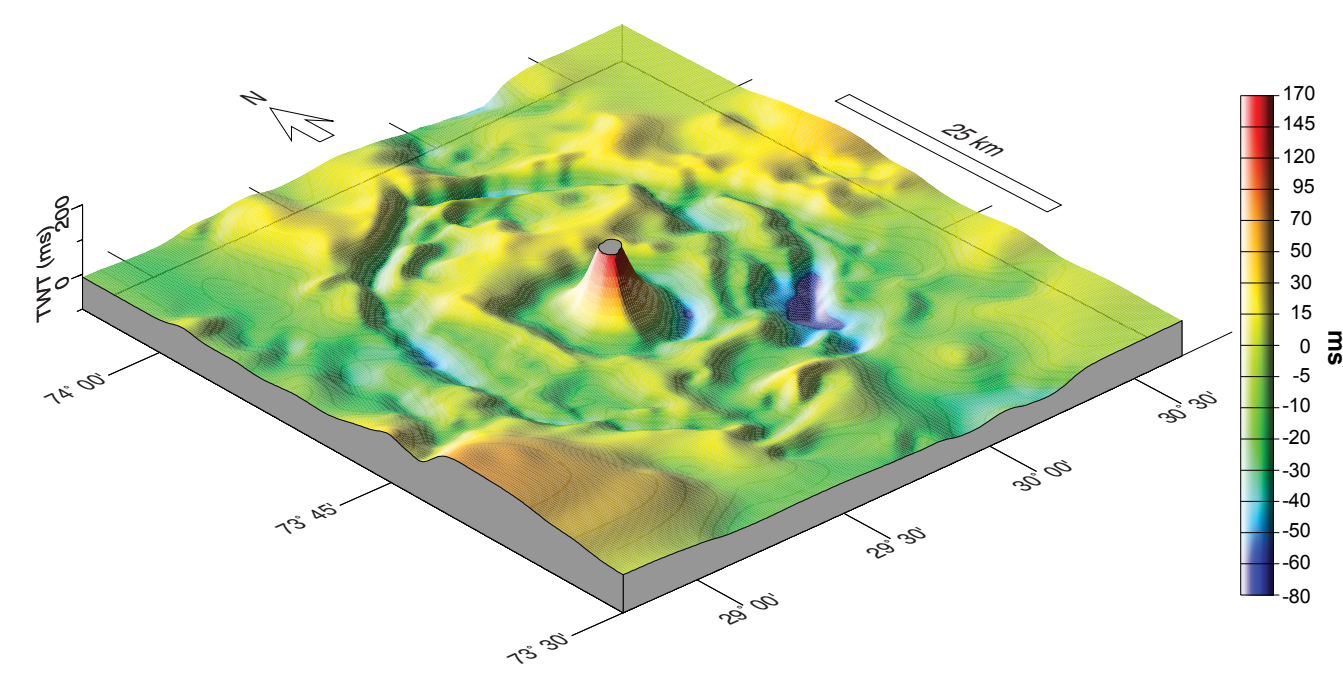

(c) Residual shipborne magnetic anomaly

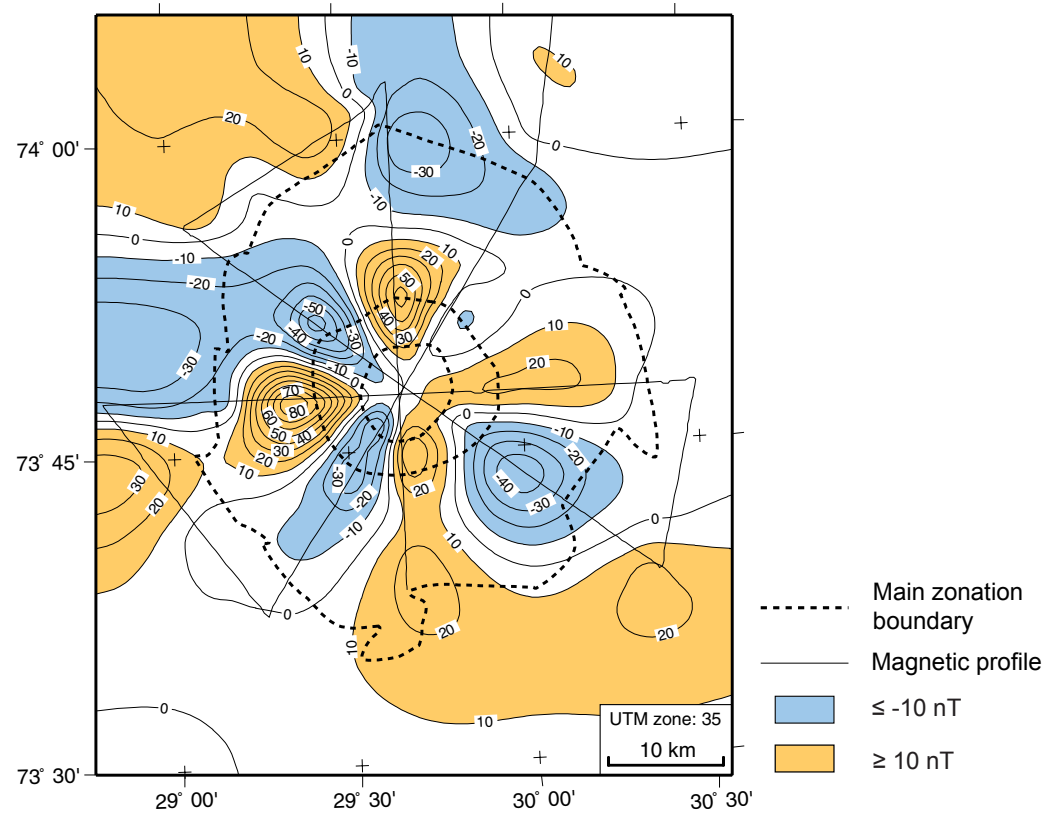

(b) Residual free-air shipborne gravity anomaly

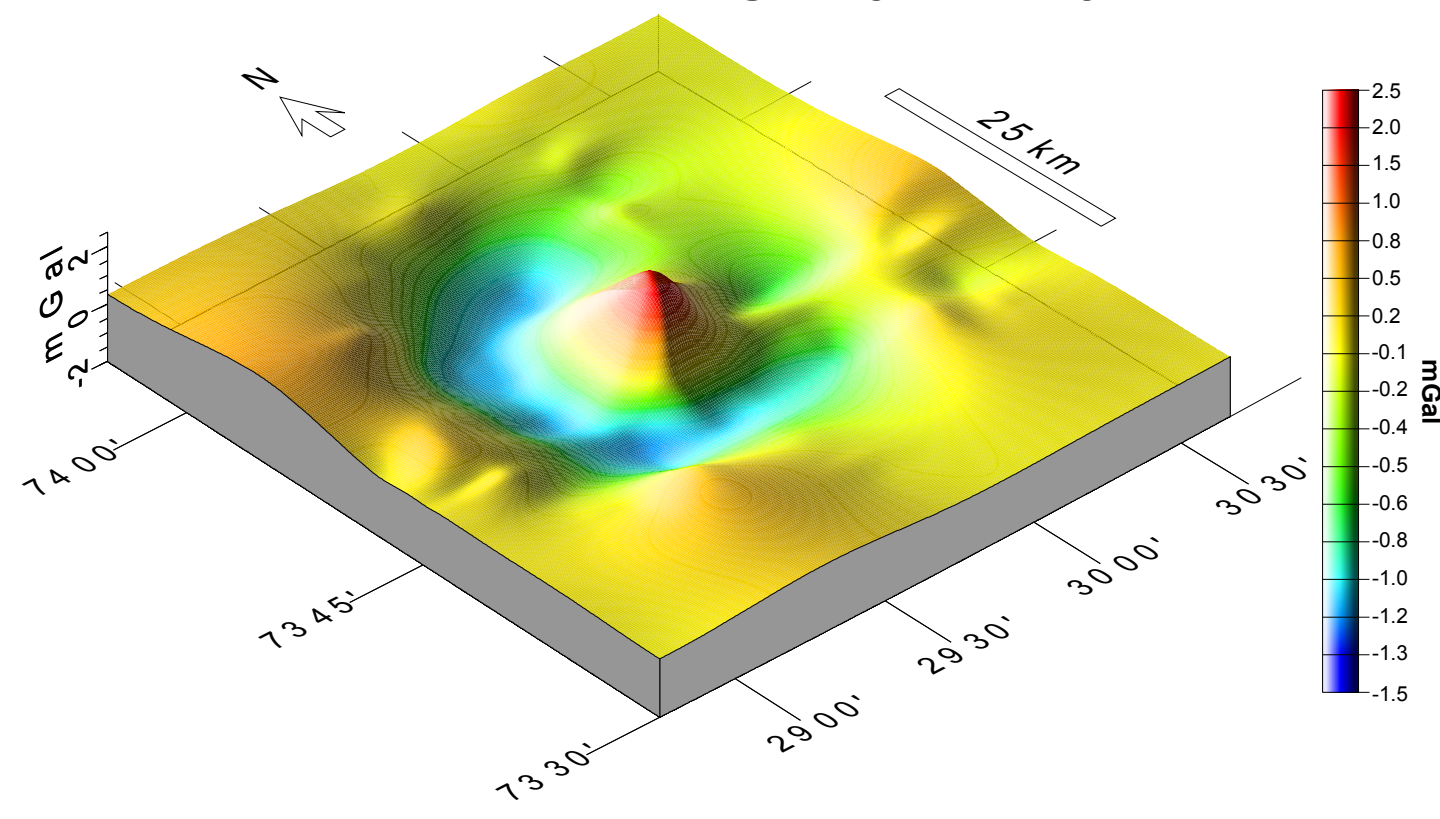

(d) Residual traveltime/velocity anomaly (at Top Permian reflector)

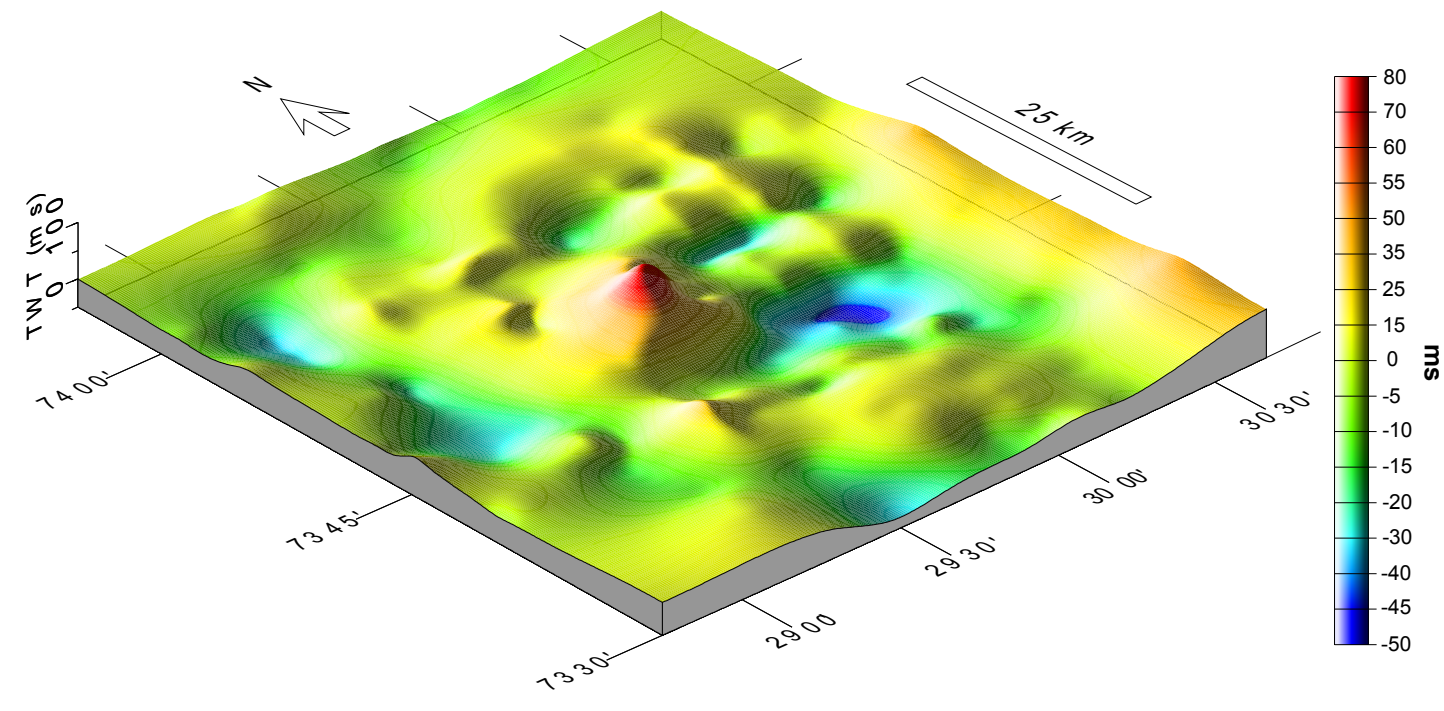


A

$\mathbf{A}^{\prime}$
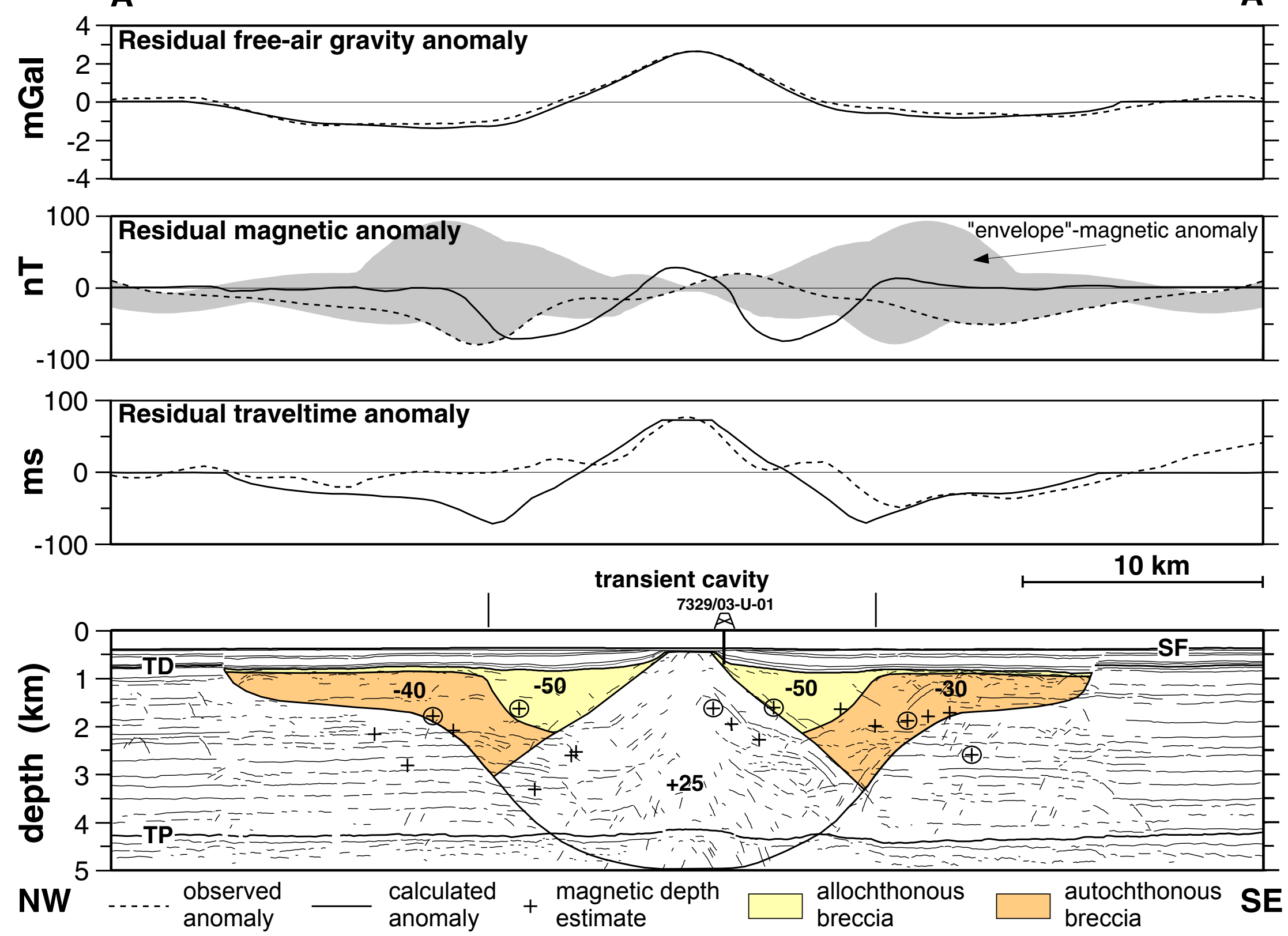

Figure 3 


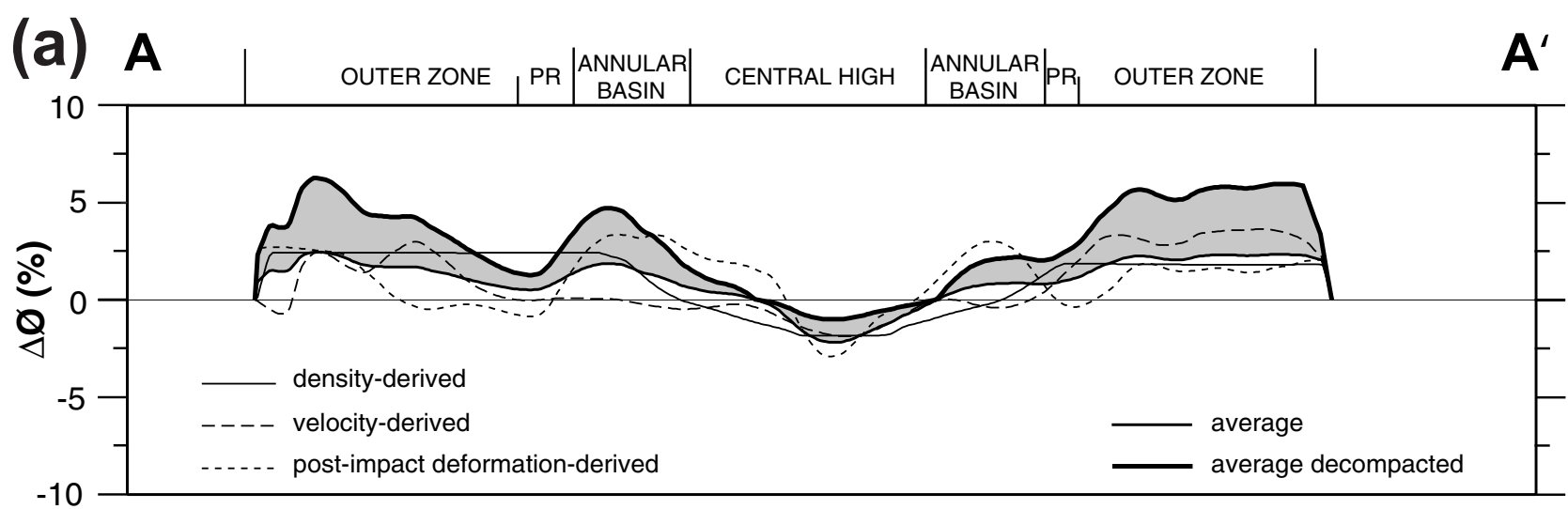

(b) Original crater

Impact-induced deformation

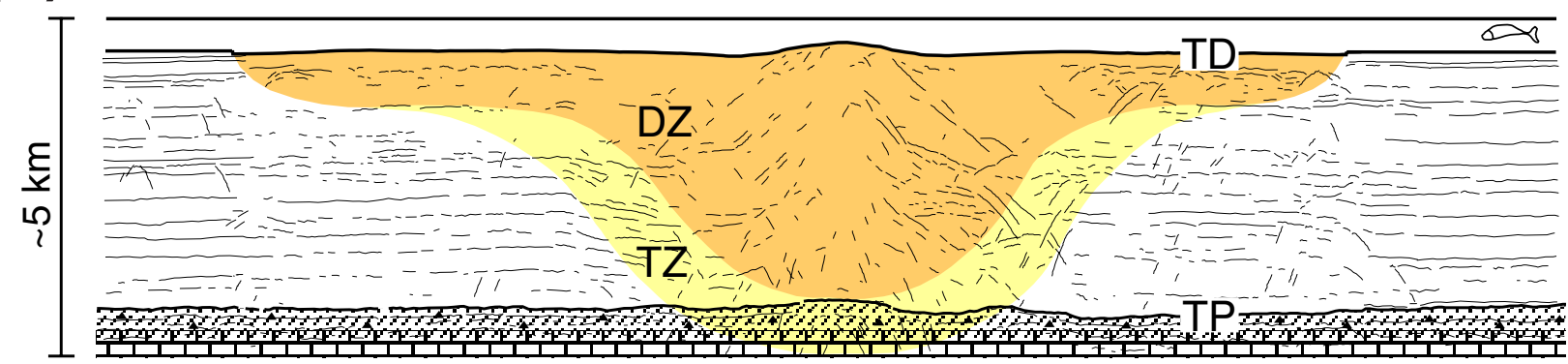

(c)
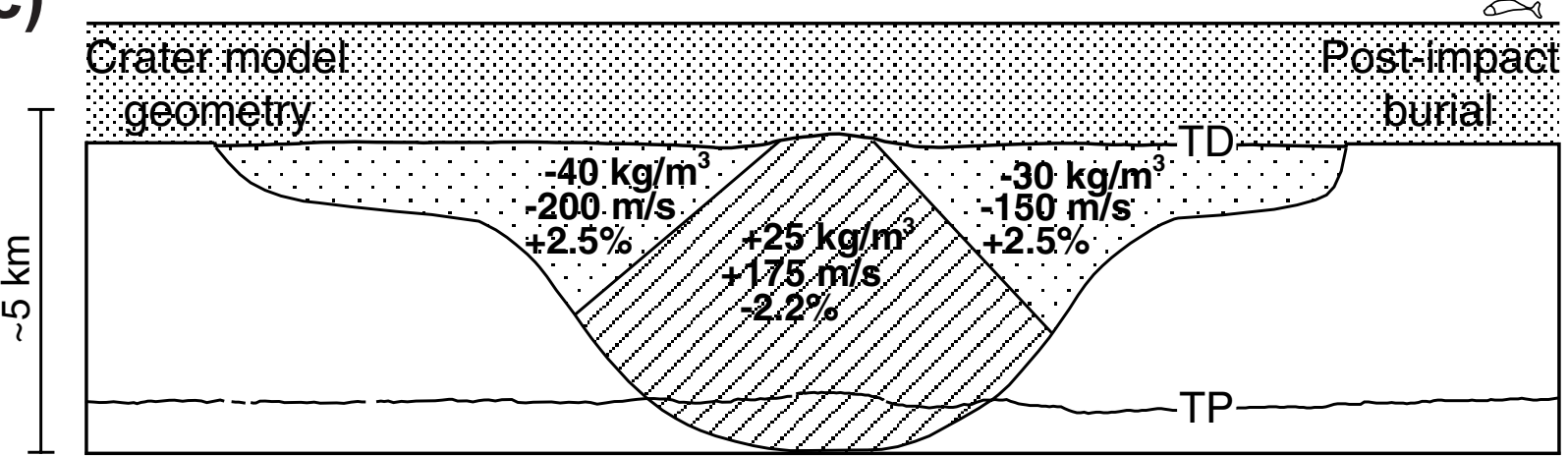

(d) Present crater

Post-impact

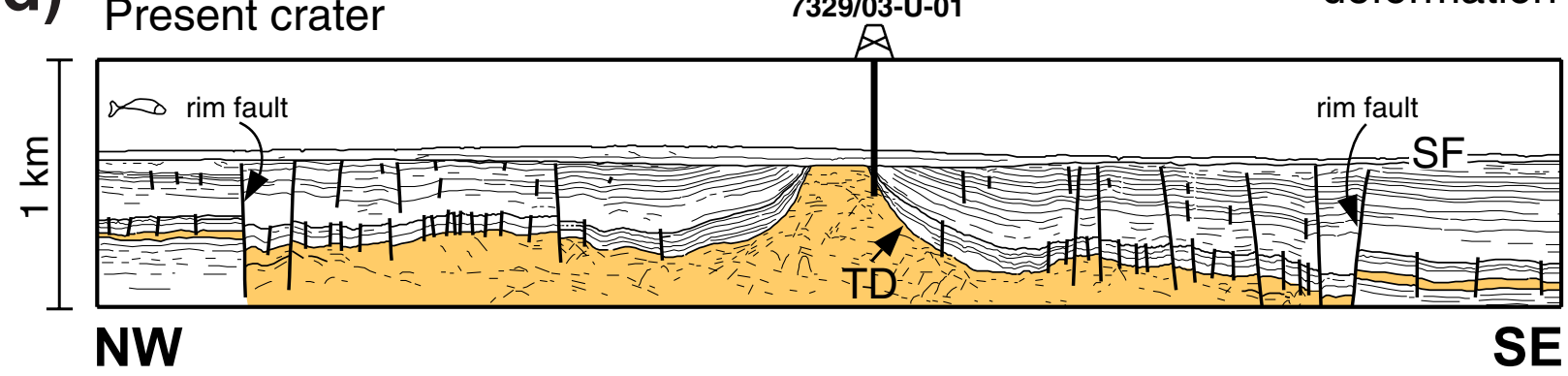

Figure 4 

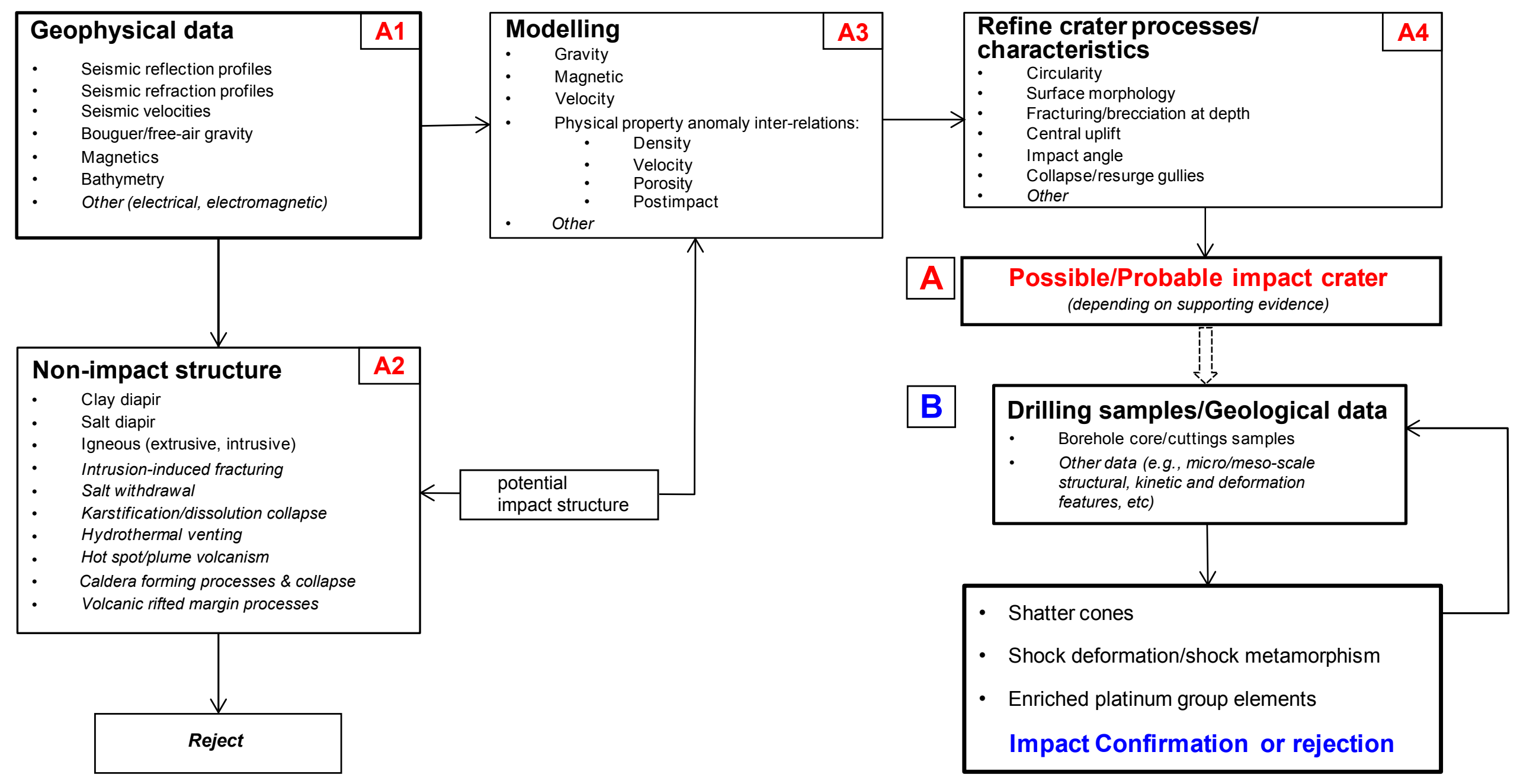

Figure 5 